\title{
Periventricular lesions and MS diagnostic criteria in young adults with typical clinically isolated syndromes
}

Wallace J. Brownlee ${ }^{1}$, Katherine A. Miszkiel ${ }^{2}$ Daniel R. Altmann ${ }^{1,3}$, Olga Ciccarelli ${ }^{1,4}$, David H. Miller ${ }^{1,4}$

${ }^{1}$ Queen Square Multiple Sclerosis Centre, Department of Neuroinflammation, UCL Institute of Neurology, London, United Kingdom

${ }^{2}$ Lysholm Department of Neuroradiology, National Hospital for Neurology and Neurosurgery, London, United Kingdom

${ }^{3}$ Medical Statistics Department, London School of Hygiene and Tropical Medicine, London, United Kingdom

${ }^{4}$ NIHR University College London Hospitals Biomedical Research Centre, London, United Kingdom

Corresponding author: Dr W Brownlee, Box 112, National Hospital for Neurology and Neurosurgery, Telephone +44 $20 \quad 3108$ 7409, Fax +44 $20 \quad 3448$ 3125, Email w.brownlee@ucl.ac.uk

Word count $=1144$ 


\section{ABSTRACT}

In patients who present with a clinically isolated syndrome (CIS) whose features are suggestive of multiple sclerosis (MS), fulfilling McDonald 2010 MRI criteria for dissemination in space (DIS) and time (DIT) enables a diagnosis of MS. While $\geq 1$ periventricular lesion is included in the 2010 DIS criteria, earlier McDonald criteria required $\geq 3$ periventricular lesions to confirm DIS and recent MAGNIMS-recommended DIS criteria also require $\geq 3$ lesions. We investigated the effect of varying the required number of periventricular lesions and found that the best combination of specificity and sensitivity for clinically definite MS was seen for $\geq 1$ periventricular lesions using both the McDonald 2010 and MAGNIMS 2016 criteria. 


\section{INTRODUCTION}

The McDonald criteria allow evidence on MRI for dissemination in space (DIS) and dissemination in time (DIT) to diagnose multiple sclerosis (MS) in patients with a clinically isolated syndrome (CIS). ${ }^{1} \mathrm{MRI}$ evidence for DIS in the McDonald 2010 criteria requires $\geq 1$ asymptomatic T2-hyperintense lesions in at least two of four regions typically affected in demyelination: periventricular, juxtacortical, infratentorial and spinal cord. ${ }^{1}$

The MAGNIMS group recently proposed new DIS criteria that include lesions in the optic nerve, cortex, and symptomatic region, in addition to an increase in the required number of periventricular lesions from $\geq 1$ to $\geq 3$. ${ }^{2}$ This latter recommendation was based on expert consensus and avoids a potential concern of reduction in specificity should the symptomatic lesion and a single periventricular lesion alone constitute evidence for DIS.

A comparison of diagnostic criteria that differ only in the required number of periventricular lesions has not been previously undertaken. We therefore investigated the performance of $\geq 1$, $\geq 2$ and $\geq 3$ periventricular lesions in the 2010 McDonald criteria for the diagnosis of clinicallydefinite MS (CDMS) in a prospective CIS cohort. The performance of the new MAGNIMS criteria was also evaluated in a subgroup of patients in whom the symptomatic region had been imaged.

\section{METHODS}

We studied 151 CIS patients (optic neuritis $n=124$, brainstem syndrome $n=18$, partial myelopathy $n=8$, hemispheric syndrome $n=1$ ) from a prospectively recruited cohort. ${ }^{3}$ Inclusion criteria were age 16-50 years, a typical CIS suggestive of MS and no previous history of 
neurological symptoms. The patients had T2-weighted and gadolinium-enhanced T1-weighted brain and spinal cord MRI within three months of symptom onset. Follow-up T2-weighted and gadolinium-enhanced $\mathrm{T} 1$-weighted brain $\mathrm{MRI}$ was done after three months. A single experienced neuroradiologist (KAM) identified the number and location of T2-hyperintense and gadolinium-enhancing lesions. Patients were followed prospectively over approximately 15 years for the development of CDMS, requiring clinical evidence of a second episode and two separate lesions. ${ }^{4}$ The study was approved by the institutional Research Ethics Committee and all patients provided informed consent.

We retrospectively applied the McDonald 2010 DIS criteria that include $\geq 1$ periventricular lesion $^{1}$ and then applied the same DIS criteria with the single modification that either $\geq 2$ or $\geq 3$ periventricular lesions were required. ${ }^{1}$ The McDonald 2010 DIT criteria ${ }^{1}$ were also applied and both DIS plus DIT were required for a diagnosis of MS.

We similarly investigated varying the number of periventricular lesions for the proposed MAGNIMS 2016 criteria $^{2}$ in the subgroup of non-optic neuritis patients $(n=27)$ who had imaging of the symptomatic region thus allowing inclusion of the symptomatic lesion when visible. ${ }^{2} \mathrm{As}$ optic nerve and double inversion recovery images were not obtained, we could not investigate the effect of optic nerve or cortical lesions.

We tested performance of the DIS criteria using $\geq 1, \geq 2$ and $\geq 3$ periventricular lesions, alone and in combination with DIT, for the development of CDMS. We calculated the sensitivity, specificity and accuracy with $95 \%$ confidence intervals $(\mathrm{Cl})$ as previously described. ${ }^{5}$ 


\section{RESULTS}

The demographic characteristics were typical of CIS patients (mean age 32.4 years, 68\% female). Over a mean follow up period of 15.1 years (range 11.0 - 19.7 years), 91 (60\%) patients developed CDMS. The number of periventricular lesions at baseline and positive predictive value for development of CDMS is shown in Table 1.

Performance of the McDonald 2010 criteria using $\geq 1, \geq 2$ and $\geq 3$ periventricular lesions for development of CDMS is shown in Table 2. $\geq 1$ periventricular lesion had the highest sensitivity and only slightly lower specificity than DIS criteria requiring $\geq 2$ or $\geq 3$ periventricular lesions. When DIS was combined with DIT, the sensitivity and accuracy of $\geq 1$ periventricular lesion was higher than $\geq 2$ or $\geq 3$ periventricular lesions and specificity was the same. Results were similar when applying the MAGNIMS 2016 criteria in the subgroup with imaging of the symptomatic region: $\geq 1$ periventricular lesion provided a higher sensitivity and the same specificity as $\geq 2$ or $\geq 3$ periventricular lesions (Table 2 ).

\section{DISCUSSION}

Increasing the number of periventricular lesions required for DIS reduced the sensitivity of the 2010 McDonald MRI criteria for a diagnosis of CDMS possibly reflecting the lower lesion load at this earliest clinical stage of MS. Although a high sensitivity is desirable in contributing to more accurate diagnosis, a high specificity is more important, in order to minimise the risk of a false positive diagnosis. There was only a slight decrease in specificity of DIS criteria alone requiring only $\geq 1$ or $\geq 2 \mathrm{PV}$ lesions rather than $\geq 3$, and when DIT criteria were added to DIS (as required for to diagnose MS), the specificity of the 2010 McDonald criteria for CDMS was the same whether the minimum number of PV lesions was 1, 2 or 3. 
The new MAGNIMS criteria include lesions in the symptomatic region in DIS (these are excluded in the McDonald 2010 criteria). ${ }^{2}$ When we included such lesions in the small subgroup of non-optic neuritis CIS ( $n=27)$, varying the number of periventricular lesions yielded similar findings to those reported for the whole cohort. A larger cohort should be studied to definitively investigate the effect of including symptomatic region lesions and varying the number of periventricular lesions. Additional cohort studies will also be needed to investigate other the other new DIS imaging features recommended by MAGNIMS.

We studied a group of young adults with well-defined presentations typical of demyelination and a high pre-test probability of MS. How MRI criteria perform outside this setting, for example, in people with atypical presentations or in older adults ( $>50$ years) is uncertain and the likelihood of alternative diagnoses may be higher. Although synonymous with MS, periventricular lesions can occur in many disorders including migraine ${ }^{6,7}$ and small vessel cerebrovascular disease. ${ }^{8}$, and a previous study found that $\geq 3$ periventricular lesions was the best MRI brain measure to differentiate MS from other neurological disorders. ${ }^{8}$ Furthermore, T2-hyperintensities anterior to the frontal horns of the lateral ventricles ("periventricular capping") and the septum pellucidum are common findings on fluid-attenuated inversion recovery (FLAIR) sequences in healthy subjects, and may be confused with MS lesions. ${ }^{9}$ Because of the limited specificity of MRI lesion location per se, it remains absolutely essential that MRI criteria for MS are only applied in clinical settings where MS is strongly suspected, such as a young adult presenting with a typical CIS (e.g. unilateral optic neuritis, partial myelopathy) in order to avoid misdiagnosis. ${ }^{1,10}$ Even in typical CIS presentations, it is also important that the diagnostic contribution of PV lesions is not overemphasised or considered in isolation because: (i) they are neither necessary nor sufficient for DIS (McDonald criteria require involvement of at least 2 of 4 clinically unaffected regions in $\mathrm{CIS}^{1}$ ) and (ii) DIT is required in addition to DIS in order to diagnose MS and the value of also requiring DIT is highlighted by the increase in specificity that we observed (Table 2). Within these caveats, our 
findings suggest that in young adult patients with a typical CIS, increasing the required number of periventricular lesions may not improve diagnostic accuracy.

\section{ACKNOWLEDGEMENTS}

Dr Josephine Swanton assisted in the analysis of MRI data. The Queen Square MS Centre is supported by the United Kingdom MS Society and the NIHR University College London Hospitals Biomedical Research Centre.

\section{REFERENCES}

1. Polman $\mathrm{CH}$, Reingold SC, Banwell $\mathrm{B}$, et al. Diagnostic criteria for multiple sclerosis: 2010 Revisions to the McDonald criteria. Ann Neurol 2011;69:292-302.

2. Filippi M, Rocca MA, Ciccarelli O, et al. MRI criteria for the diagnosis of multiple sclerosis: MAGNIMS consensus guidelines. Lancet Neurol 2016; 15:292-303.

3. Swanton J, Fernando K, Dalton C, et al. Early MRI in optic neuritis: the risk for clinically definite multiple sclerosis. Mult Scler 2010;16:156-165.

4. Poser CM, Paty DW, Scheinberg L, et al. New diagnostic criteria for multiple sclerosis: guidelines for research protocols. Ann Neurol 1983;13:227-231.

5. Dalton CM, Brex PA, Miszkiel KA, et al. Application of the new McDonald criteria to patients with clinically isolated syndromes suggestive of multiple sclerosis. Ann Neurol 2002;52:47-53.

6. Absinta M, Rocca MA, Colombo B, et al. Patients with migraine do not have MRIvisible cortical lesions. J Neurol 2012;259:2695-2698.

7. Liu S, Kullnat J, Bourdette D, et al. Prevalence of brain magnetic resonance imaging meeting Barkhof and McDonald criteria for dissemination in space among headache patients. Mult Scler 2013;19:1101-1105.

8. Nielsen JM, Korteweg T, Barkhof F, Uitdehaag BM, Polman $\mathrm{CH}$. Overdiagnosis of multiple sclerosis and magnetic resonance imaging criteria. Ann Neurol 2005;58:781-783.

9. Neema M, Guss ZD, Stankiewicz JM, Arora A, Healy BC, Bakshi R. Normal findings on brain fluid-attenuated inversion recovery MR images at 3T. AJNR Am J Neuroradiol 2009;30:911-916. 
10. Solomon AJ, Klein EP, Bourdette D. "Undiagnosing" multiple sclerosis: the challenge of misdiagnosis in MS. Neurology 2012;78:1986-1991. 
Table 1. Number of periventricular lesions at baseline and positive predictive value (PPV) of periventricular lesions for the development of CDMS.

\begin{tabular}{lccc}
\hline & $\begin{array}{c}\text { All patients } \\
(\mathrm{n}=151)\end{array}$ & $\begin{array}{c}\text { CDMS } \\
(\mathrm{n}=91)\end{array}$ & PPV \\
\hline 0 lesions, $\mathrm{n}(\%)$ & $49(32)$ & $12(13)$ & $25 \%$ \\
1 lesion, $\mathrm{n}(\%)$ & $22(15)$ & $15(16)$ & $68 \%$ \\
2 lesions, $\mathrm{n}(\%)$ & $12(8)$ & $9(10)$ & $75 \%$ \\
$\geq 3$ lesions, $\mathrm{n}(\%)$ & $68(45)$ & $55(60)$ & $81 \%$ \\
\hline
\end{tabular}

Abbreviations: $\mathrm{CDMS}=$ clinically-definite multiple sclerosis; $\mathrm{PPV}=$ positive predictive value 
Table 2. Performance of diagnostic criteria for development of clinically-definite MS with varying numbers of periventricular lesions.

\begin{tabular}{|c|c|c|c|c|c|c|}
\hline & \multicolumn{3}{|c|}{$\begin{array}{l}2010 \text { McDonald criteria in all patients } \\
\qquad(\mathrm{n}=151)\end{array}$} & \multicolumn{3}{|c|}{$\begin{array}{l}\text { New MAGNIMS-recommended criteria in the } \\
\text { subgroup with symptomatic region MRI } \\
\qquad(\mathrm{n}=27)\end{array}$} \\
\hline & $\begin{array}{l}\text { Sensitivity } \\
(95 \% \mathrm{Cl})\end{array}$ & $\begin{array}{l}\text { Specificity } \\
(95 \% \mathrm{Cl})\end{array}$ & $\begin{array}{l}\text { Accuracy } \\
(95 \% \mathrm{Cl})\end{array}$ & $\begin{array}{l}\text { Sensitivity } \\
(95 \% \mathrm{Cl})\end{array}$ & $\begin{array}{l}\text { Specificity } \\
(95 \% \mathrm{Cl})\end{array}$ & $\begin{array}{l}\text { Accuracy } \\
(95 \% \mathrm{Cl})\end{array}$ \\
\hline \multicolumn{7}{|l|}{ DIS only } \\
\hline$\geq 1$ PV lesion & $\begin{array}{c}81 \% \\
(72-89 \%)\end{array}$ & $\begin{array}{c}72 \% \\
(59-83 \%)\end{array}$ & $\begin{array}{c}77 \% \\
(70-84 \%)\end{array}$ & $\begin{array}{c}100 \% \\
(75-100 \%)\end{array}$ & $\begin{array}{c}64 \% \\
(35-87 \%)\end{array}$ & $\begin{array}{c}78 \% \\
(62-94 \%)\end{array}$ \\
\hline$\geq 2$ PV lesions & $\begin{array}{c}74 \% \\
(63-82 \%)\end{array}$ & $\begin{array}{c}75 \% \\
(62-85 \%)\end{array}$ & $\begin{array}{c}74 \% \\
(66-81)\end{array}$ & $\begin{array}{c}85 \% \\
(55-98 \%)\end{array}$ & $\begin{array}{c}64 \% \\
(35-87 \%)\end{array}$ & $\begin{array}{c}74 \% \\
(54-89 \%)\end{array}$ \\
\hline$\geq 3$ PV lesions & $\begin{array}{c}70 \% \\
(60-79 \%)\end{array}$ & $\begin{array}{c}77 \% \\
(64-87 \%)\end{array}$ & $\begin{array}{c}73 \% \\
(65-80 \%)\end{array}$ & $\begin{array}{c}77 \% \\
(46-95 \%)\end{array}$ & $\begin{array}{c}64 \% \\
(35-87 \%)\end{array}$ & $\begin{array}{c}70 \% \\
(50-86 \%)\end{array}$ \\
\hline DIS + DIT combin & & & & & & \\
\hline$\geq 1 \mathrm{PV}$ lesion & $\begin{array}{c}64 \% \\
(53-74 \%)\end{array}$ & $\begin{array}{c}78 \% \\
(66-88 \%)\end{array}$ & $\begin{array}{c}70 \% \\
(62-77 \%)\end{array}$ & $\begin{array}{c}92 \% \\
(64-100 \%)\end{array}$ & $\begin{array}{c}71 \% \\
(42-92 \%)\end{array}$ & $\begin{array}{c}81 \% \\
(62-94 \%)\end{array}$ \\
\hline$\geq 2$ PV lesions & $\begin{array}{c}57 \% \\
(46-67 \%)\end{array}$ & $\begin{array}{c}78 \% \\
(66-88 \%)\end{array}$ & $\begin{array}{c}66 \% \\
(57-73 \%)\end{array}$ & $\begin{array}{c}85 \% \\
(55-98 \%)\end{array}$ & $\begin{array}{c}71 \% \\
(42-92 \%)\end{array}$ & $\begin{array}{c}78 \% \\
(58-91 \%)\end{array}$ \\
\hline$\geq 3$ PV lesions & $\begin{array}{c}55 \% \\
(44-65 \%)\end{array}$ & $\begin{array}{c}78 \% \\
(66-88 \%)\end{array}$ & $\begin{array}{c}64 \% \\
(56-72 \%)\end{array}$ & $\begin{array}{c}77 \% \\
(46-95 \%)\end{array}$ & $\begin{array}{c}71 \% \\
(42-92 \%)\end{array}$ & $\begin{array}{c}74 \% \\
(54-89 \%)\end{array}$ \\
\hline
\end{tabular}

Abbreviations: $\mathrm{DIS}$ = dissemination in space; DIT = dissemination in time; $\mathrm{PV}=$ periventricular 